\title{
Injury profile among elite male youth soccer players in a Swedish first league
}

\author{
Tania Nilsson'1, Anna Hafsteinsson Östenberg', Marie Alricsson ${ }^{1,2 * *}$ \\ 'Department of Sports Science, Linnaeus University, Kalmar/Näxjö, Sweden \\ ${ }^{2}$ Swedish Winter Sport Research Centre, Department of Health Sciences, Mid Sweden University, Östersund, Sweden
}

This study investigated the injury profile among elite male youth soccer players in a Swedish first league during two seasons. The present cohort study is based on data collected during the 2013-2014 seasons. In total, 43 young elite male soccer players, aged 15 to $19 \mathrm{yr}$, were prospectively followed regarding injuries, time of exposure, injury location, type of injury, and injury severity. The overall incidence of injury in the present study was estimated to 6.8 injuries per 1,000 exposure hours and 15.5 and 5.6 injuries per 1,000 hr for matches and training, respectively. The single most common injury subtype was muscle strain (53\%).
The hip and groin were the most common locations for injuries. Thirty-one percent of the injuries were classified as severe injury and caused $>28$ days absence from training and match play. Both the injury incidence and the number of serious injury seems to be relatively high in youth elite players according to this study. Although the injury incidence seems to be slightly lower than in adult elite players the injuries seem to be more traumatic in youth elite players.

Keywords: Junior soccer injuries, Male athletes, Sport injuries

\section{INTRODUCTION}

Soccer is the most common sport worldwide and has around 22 million licensed players who are under $18 \mathrm{yr}$ old, according to Federation of the International Football Associations (FIFA) (FIFA Communications Division Information Services, 2007).

Many hours of dedicated practice are needed to attain an expert level of performance in soccer (Ford et al., 2009). Many studies about incidence of injuries among youth soccer players of differing ages and skill levels have been published, and the injury incidence varies mostly between 4.8 and 5.6 injuries per 1,000 hr of exposure for players aged 12-18 yr (Emery et al., 2005; Ergün et al., 2013; Froholdt et al., 2009; Le Gall et al., 2006; Le Gall et al., 2007; Price et al., 2004). The injury incidence among youth soccer players seems to increase with age (Emery et al., 2005; Froholdt et al., 2009; Le Gall et al., 2006; Le Gall et al., 2007). This increase in injury incidence may be due to the increasing exercise frequency, exercise intensity and total load of soccer that occurs as players get older and strive to be top quality players (Emery et al.,
2005; Timpka et al., 2008). Van der Sluis et al. (2014) suggest that growth and maturation are potential risk factors for sport injury in talented soccer players. The period of maximal rate of growth termed peak height velocity (PHV) seems to result in increased vulnerability for traumatic injuries, while in the period after PHV players seem susceptible for overuse injuries.

Most of the injuries in youth soccer players affect lower extremities, regardless of the players' gender and level in soccer (Clausen et al., 2014; Emery et al., 2005; Ergün et al., 2013). The ankle and knee have proven to be the most common injury location among youth soccer players (Emery et al., 2005; Le Gall et al., 2007).

Reports on the most common type of injury among elite youth soccer players vary between different studies. Le Gall et al. (2007) report that the most common types of injuries in their study were contusions, sprains and strains. Similar findings were obtained by Le Gall et al. (2006). Ergün et al. (2013) who investigated the most common injury type among national elite youth soccer players found that muscle strain was the most common injury type.

Sport injuries can lead to reduced participation in sports activi-
${ }^{*}$ Corresponding author: Marie Alricsson (iD http://orcid.org/0000-0001-6653-3414 Department of Sports Science, Linnaeus University, SE-391 82 Kalmar, Sweden Tel. +46-738012299, Fax: +46-480446955, E-mail: marie.alricsson@lnu.se Received: January 13, 2016 / Accepted: March 11, 2016
This is an Open Access article distributed under the terms of the Creative Commons Attribution Non-Commercial License (http://creativecommons.org/licenses/by-nc/4.0/) which permits unrestricted non-commercial use, distribution, and reproduction in any medium, provided the original work is properly cited. 
ties and reduced physical activity level for the affected individual. Sports injuries are also common reason as to why an individual's sports career ends (Ekstrand et al., 1990). It has also been shown that sports injuries, especially knee and ankle injuries, pose increased risk for development of osteoarthritis (Daniel et al., 1994; Gillquist and Messner, 1999; Lohmander et al., 2004; von Porat et al., 2004).

Few studies have examined injury incidence among elite youth soccer players who were training full-time with the aim of becoming professional players (Price et al., 2004). To the best of our knowledge, no study has examined this before in a Swedish first league. Continuous data are needed to identify injury incidence and profiles, particularly from elite levels, with respect to trends over time.

The aim of the present study was to investigate the injury profile in male youth soccer players at elite level during two seasons.

\section{MATERIALS AND METHODS}

\section{Participants}

This cohort study is based on data collected from Swedish elite youth soccer players over a period of two seasons, from January 2013 to December 2014. All players in the present study played elite soccer at youth level in a Swedish first league. In total, 43 young elite male soccer players with mean age $17.7 \mathrm{yr}$ (range, 15$19 \mathrm{yr}$ ), mean height $181 \mathrm{~cm}$ (range, 168-196 cm) and mean weight $75 \mathrm{~kg}$ (range, 64.5-90 kg) participated in the study. The players were prospectively followed regarding injuries, time of exposure, injury location, type of injury and injury severity. All injuries that occurred during the study period were registered using an injury card, which follows the recommendations made by FIFA in the International consensus agreements on procedures for epidemiological studies of football injuries (Hägglund et al., 2005a).

Ethical approval was obtained from the Ethical Advisory Board in South East Sweden (Dnr EPK 253-2014).

\section{Inclusion criteria}

Participants in the present study: (a) played elite soccer at youth level in Youth-19 in a Swedish first league for at least 6 months during the years 2013-2014, (b) were aged 15 to $19 \mathrm{yr}$ when the data were collected, (c) were male, and (d) had given consent to participate in the study.

Players with an existing injury at start of the present study were also included in the injury statistics, but their particular injury was not included in the injury statistics, and the exposure details were not included until the player could take part in full training and match, according to recommendations made by Hägglund et al. (2005a).

\section{Injury definitions}

Injury definition used in this study followed recommendations made by the International Injury Consensus Group; injuries resulting in the player being unable to fully participate in future soccer training or match was classified as time-loss injury (Fuller et al., 2006). The soccer season consisted of preseason period from January to March, followed by competitive season from April to November. All injuries that occurred to the participants were examined by a physiotherapist in the team. The physiotherapist performed clinical assessment according to usual medical tests to confirm the diagnosis/injury. Ultrasound diagnostics were used on a few occasions as complement to the clinical examination. Injury incidence was calculated as number of injuries per 1,000 hr of exposure in training and matches (Hägglund et al., 2005a).

Definition of injury severity in the present study followed recommendations made by the International Injury Consensus Group and is defined as number of days that have elapsed from date of injury to date of player's return to full participation in team training and availability for match selection (Fuller et al., 2006).

The injuries were categorised as minimal injury (1-3 days absence), minor injury (4-7 days absence), moderate injury (8-28 days absence) and major/severe injury ( $>28$ days absence) (Hägglund et al., 2005a).

All injuries in the present study were followed by the team physiotherapist until rehabilitation was fully completed. If a player could only participate in part of the session, he was recorded as injured. A player was considered injured until he was given clearance by the team physiotherapist to participate fully in team training and match (Hägglund et al., 2005a).

\section{Procedure}

Exposure time was measured and recorded for each player as number of minutes of exposure, all training sessions and matches included. The exposure form used in the present study is called "Swedish national injury register" and follows guidelines recommended by the Union of European Football Associations (UEFA) and FIFA in the international consensus agreements on epidemiological studies of soccer injuries (Fuller et al., 2006; Hägglund et al., 2005a). All players in the current youth soccer team were informed about the exposure registration before the start of the registration.

All injuries were documented twice a week on a standard injury 
card. The injury card provided information on date of the injury, date of return to full participation, if it was a training or match injury and injury type, side and location. Injury severity was graded according to number of days of absence from training and match play (Ekstrand et al., 2011; Hägglund et al., 2005a).

\section{Statistical analysis}

The exposure and injury forms that were collected during the study were decoded and then recorded. The analysis of the collected data was performed using a statistical programme, IBM SPSS Statistics ver. 22.0 (IBM Co., Armonk, NY, USA). Results are presented in figures and tables. Descriptive statistics are presented as mean $(\mathrm{X})$, standard deviations and percents. Injury incidence was calculated as number of injuries per 1,000 hr of exposure in training and/or matches.

\section{RESULTS}

\section{Exposure and incidence of injury}

At the start of the study, all participants were free of injury, and the study did not have any dropouts. In total, 10,368 hr of exposure were registered over the two seasons January-December 2013-2014 (Fig. 1). The attendance rate at training was $89 \%$ for both seasons. In total, 61 injuries were recorded during the 20132014 seasons, with an injury prevalence of 0.7 injuries per player and season. In sum, 18 injuries occurred during matches and 43 injuries occurred during training (Table 1). The overall incidence of injury in the present study was estimated to 6.8 injuries per 1,000 exposure hours and 15.5 and 5.6 injuries per 1,000 $\mathrm{hr}$ for matches and training, respectively. The highest incidence of inju-

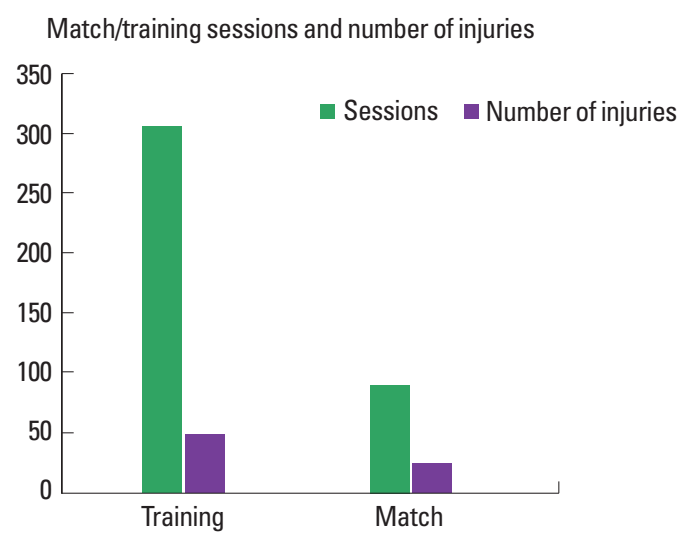

Fig. 1. The figure shows the number of training sessions/games and the number of injuries that affected the youth elite soccer players in a Swedish premier league association during the years 2013-2014. ries occurred in May.

\section{Injury location and type of injury}

The hip and groin were the most common locations for injuries, representing 33\% (20 of 43) of all injuries. Other common injury locations were the thigh, representing $26 \%$ (16 of 43 ) of all injuries, and the ankle, representing 18\% (11 of 43) of all injuries (Fig. 2).

Injuries affecting the lower extremities represented $93 \%$ of all injuries in the present study. The concept of lower extremity included injuries to the hip/groin, thigh, knee, lower leg/Achilles tendon, ankle, and foot/toes.

The single most common injury subtype was muscle strain, representing 53\% (31 of 43) of all injuries (Fig. 3). Sprain was the second most common injury subtype representing $24 \%$ (15 of 43) of all injuries.

\section{Injury mechanism and severity}

Injury mechanisms are shown in Table 2. The player's absence from training and match due to injury (Fig. 4) was estimated according to the model created by Ekstrand et al. (2011). During

Table 1. Exposure time, attendance at training and number of injuries that affected the youth elite soccer players in a Swedish first league during the years 2013-2014

\begin{tabular}{lccccc}
\hline Year & $\begin{array}{c}\text { No. of } \\
\text { activities }\end{array}$ & $\begin{array}{c}\text { Training hours } \\
\text { per player (hr) }\end{array}$ & $\begin{array}{c}\text { Exposure } \\
\text { hours (hr) }\end{array}$ & $\begin{array}{c}\text { Attendance at } \\
\text { training and } \\
\text { match (\%) }\end{array}$ & $\begin{array}{c}\text { No. of } \\
\text { injuries }\end{array}$ \\
\hline 2013 & 195 & 266 & 5,169 & 87 & 31 \\
2014 & 202 & 261 & 5,198 & 85 & 30 \\
Total & 397 & 527 & 10,367 & 86 & 61 \\
\hline
\end{tabular}

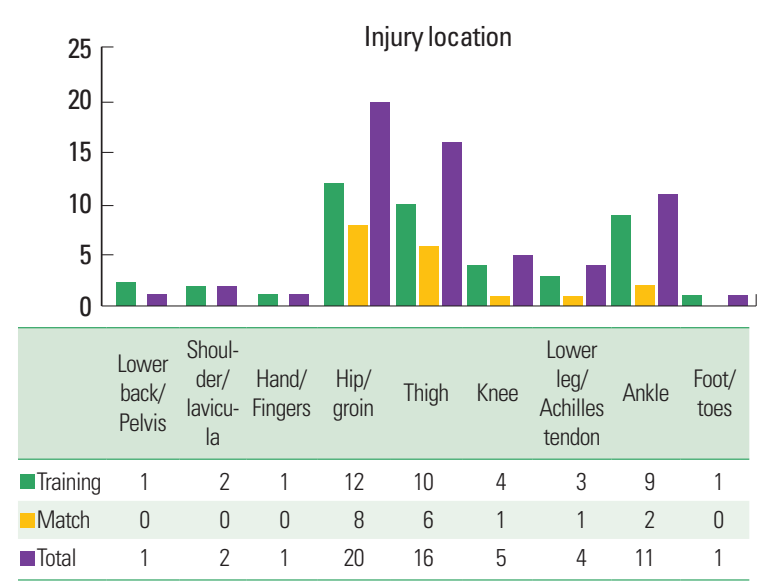

Fig. 2. The figure shows the different injury locations for the injuries that affected the youth elite soccer players in a Swedish premier league association during the years 2013-2014. 


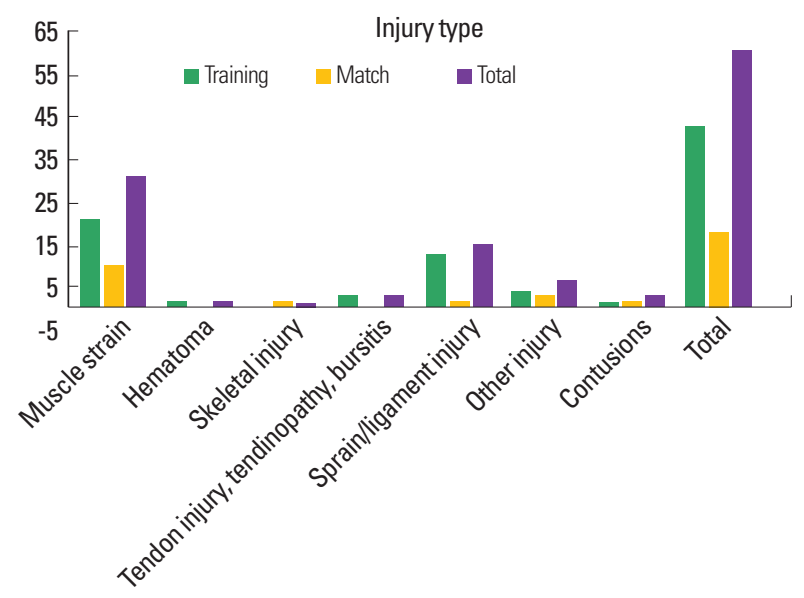

Fig. 3. The figure shows the different types of injury that affected the youth elite soccer players in a Swedish premier league association during the years 2013-2014.

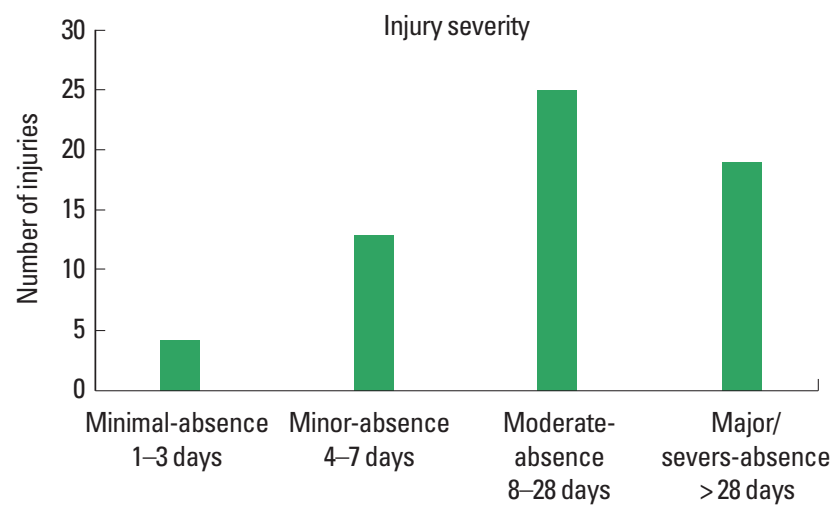

Fig. 4. The figure shows the injury severity and days of absence caused by injury for the youth elite soccer players in a Swedish premier league association during the years 2013-2014.

the registration period, $7 \%$ ( 4 of 61 ) of the injuries were estimated as a minimal injury while $21 \%$ ( 13 of 61 ) of the injuries were estimated as a minor injury. Of all registered injuries, $41 \%$ (25 of 61) of the injuries were estimated as a moderate injury and $31 \%$ (19 of 61) of the injuries as a major/severe injury, with over 28 days of absence from training and match.

\section{DISCUSSION}

The present study investigated the injury profile among elite male youth soccer players in a Swedish first league during two seasons. The study shows that the injury incidence was 6.8 injuries per 1,000 $\mathrm{hr}$ of exposure time and $31 \%$ of the injuries were classified as severe injury and caused $>28$ days absence from
Table 2. Injury mechanism in elite youth soccer players in a Swedish first league during the years 2013-2014

\begin{tabular}{lc}
\hline Injury mechanism & Total \\
\hline Running/sprint & 17 \\
Turning/rotation & 1 \\
Shot & 6 \\
Pass & 1 \\
Hop/landing & 4 \\
Fall & 5 \\
Stretching after ball & 2 \\
Overload & 10 \\
Collision & 2 \\
Tackled by opponents & 2 \\
Kick/knee from opponents & 3 \\
Blocking & 2 \\
Other acute mechanism & 1 \\
Unknown mechanism & 5 \\
Total & 61 \\
\hline
\end{tabular}

training and match play. Both the injury incidence and the number of serious injury seems to be relatively high in elite male youth soccer players in a Swedish first league according to this study, which differ from previous studies on youth soccer players.

In sum, 61 injuries were recorded during the 2013-2014 seasons, which means that a player sustained approximately 0.7 injuries per season. This may be related to the study by Ekstrand et al. (2011), which showed that a senior male soccer player at professional level suffered two injuries per season on average.

The same study has also shown that the incidence of injury in male professional soccer at senior level amounts to 8 injuries per 1,000 exposure hours (Ekstrand et al., 2011), which can be compared with the present study, where injury incidence was 6.8 injuries per 1,000 hr of exposure. The number of injuries per season at an elite male youth soccer team can, therefore, be assumed to be lower, compared to a professional male senior soccer team. The professional male senior soccer team had approximately 160 training sessions per season (Ekstrand et al., 2011), compared to the elite male youth soccer team in the present study with approximately 151.5 training sessions per season. Taking these numbers into account, one can assume that exercise frequency should not be an underlying cause for the senior team's higher incidence of injury. Instead, factors such as higher exercise intensity and higher load on each individual player most likely contribute to a higher incidence of injury in senior soccer players, compared to the youth soccer team.

Emery et al. (2005) noted that their soccer players aged 12-18 
yr had an incidence of 5.59 injuries per 1,000 hr of exposure. However, their study included both male and female players; moreover, the players were active in lower divisions than the players in the present study, and the players were followed only during their competition season and not during the preseason. This means that all injuries during the preseason had been excluded, which may contribute to the lower incidence of injury. Furthermore, the players in the present study had a higher training frequency with 5-6 training sessions/week, compared to the group in the study by Emery et al. (2005) where there was only $2-4$ training sessions/wk, which may contribute to the slightly higher incidence of injury in the present study.

Growth and maturation are potential risk factors for sport injury in talented soccer players (Van der Sluis et al., 2014), which also may contribute to the higher injury incidence among the elite soccer players.

The present study has shown that out of all injuries in the elite male youth soccer team, 18 injuries occurred during match play and 43 during training. The incidence of injury during match was estimated to 15.5 injuries per 1,000 hr and 5.6 injuries per $1,000 \mathrm{hr}$ of training. The fact that the injury incidence is higher during match play than in training is consistent with previous studies in professional male senior teams (Ekstrand et al., 2011; Hägglund et al., 2005b; Waldén et al., 2005a). Ergün et al. (2013) have shown that injury incidence was significantly higher during matches, compared to during training in a national male youth soccer team, which is consistent with the results of the present study. The injury incidence among young soccer players seems to increase with age (Emery et al., 2005; Froholdt et al., 2009; Le Gall et al., 2006; Le Gall et al., 2007), which may be due to the increasing exercise frequency, exercise intensity and total load of soccer that occurs as players get older and strive to be top quality players (Emery et al., 2005; Timpka et al., 2008). Physical stress and a disturbed stress-recovery balance appears to play an important role in relation to the occurrence of both injuries and illnesses (Brink et al., 2010).

The thigh has proven to be the most common injury location among male professional senior soccer players (Ekstrand et al., 2011), and the ankle and knee have proven to be the most common injury locations among young soccer players of both sexes (Emery et al., 2005; Mohib et al., 2014). In the present study, the hip and groin were the most common location of injury, followed by thigh and ankle injuries.

Muscle strain has proved to be the most common type of injury in several studies (Brito et al., 2012; Ekstrand et al., 2011; Ergün et al., 2013; Mohib et al., 2014; Waldén et al., 2005a; Waldén et al., 2005b). In the present study, muscle strain accounted for $53 \%$ of all injuries and was calculated as the most common type of injury among elite male youth soccer players, which is consistent with the results mentioned above.

In total, $31 \%$ of the injuries in this study were rated as major/ severe injury and generated $>28$ days of absence from soccer. This result differs from other previous studies on youth soccer players, where most of the injuries were rated as minimal or minor injury and generated 1-7 days of absence from soccer (Froholdt et al., 2009). According to Ekstrand et al. (2011), $16 \%$ of all injuries in a professional male senior soccer team are major/severe injuries. A professional male senior soccer team can, therefore, expect 8 major/severe injuries per season, while the results from the present study indicate that an elite male youth soccer team in a Swedish first league can expect 9.5 major/severe injuries per season. More studies are needed in this area to determine why the elite male youth soccer players suffer more major/severe injuries, compared to both younger soccer players and professional male senior soccer players. To decrease the number of serious injuries among elite male youth soccer players, preventive actions need to be taken. Emery and Meeuwisse (2010) showed that a specific soccer neuromuscular training programme, including dynamic stretching, eccentric strength exercises, jump exercises and balance exercises may reduce injuries in indoor soccer teams. Brink et al. (2010) suggests that monitoring stress and recovery and incidence of medical problems in elite youth soccer players by means of daily logs and monthly questionnaires may play a role in a prevention strategy for injuries and illnesses in elite youth soccer players. More research is needed to investigate what form of preventive actions should be initiated to reduce number of serious injuries in elite male youth soccer players.

Only injuries that occurred during the elite male youth soccer team's activities were included in the study. The concept of team activities included all matches and trainings in the soccer team's auspices, which included both soccer training and strength training (Hägglund et al., 2005a). The definitions of injury, injury severity, injury classification and type of injury are well established by both UEFA and FIFA (Fuller et al., 2006; Hägglund et al., 2005a).

Injury risk and pattern vary over the soccer season (Ekstrand and Gillquist, 1983; Woods et al., 2002), which is why the study period should include the entire season or several seasons, including both the preseason and competitive season (Hägglund et al., 2005a). Therefore, the authors of the present study chose to follow 
the participants during two full seasons (2013-2014). The seasons consisted of preseason period from January to March, followed by competitive season from April to November.

Inclusion criteria for participation in the present study was that the youth soccer player played elite soccer at youth level in Youth-19 in a Swedish first league for at least 6 months during 2013-2014. This limit of 6 months was used to exclude test players who participated in very few training sessions with the soccer team. Other criteria were that the participants should be male and aged 15-19 yr, with the aim that the study group should be as homogeneous as possible. Data were collected continuously over the years 2013-2014 and injuries were registered as described in the method section.

A limitation of the study is the small sample size, which is explained by the fact that there were no more players in the team available to be included in the study. The relative short study period can also be seen as a limitation of the study, and to obtain an even more reliable result in further research, longer study periods are recommended. The team physiotherapist performed a clinical assessment according to usual medical tests to establish the diagnosis/injury, which entails a risk that the injuries may have been wrongly assessed. Thus, one strength of this study is that the same physiotherapist assessed all injuries, which reduces the risk of miscalculations and errors in the injury protocol.

Only on a few occasions was ultrasound used as a complement to the clinical examination, due to the major cost that an ultrasound examination cause. To ensure an accurate diagnosis, see the exact injury localisation and make a more reliable assessment of the injury (Slavotinek, 2010; Weatherall and Crues 3rd, 1995), ultrasound diagnostics would have been desirable to use for all injuries that occurred in the study group during the study period.

Since soccer is the most common sport worldwide and since sports injuries have been shown to result in future disorders for the affected youth soccer player, it is important to be able to identify the incidence of injury in a male youth soccer team at elite level. The results of this study can be used as a basis for future studies to develop preventive programmes and reduce the number of sports injuries in youth soccer players. In future studies on the same topic, a larger study group is necessary to ensure the present studies results regarding injury incidence, injury location and type of injury in youth elite male soccer players.

The results of the study show that the injury incidence was 6.8 injuries per 1,000 hr exposure in the elite male youth soccer team. Thirty-one percent of the injuries were classified as major/severe injury and caused $>28$ days absence from training and match play. Both the injury incidence and the number of serious injury seems to be relatively high in elite youth players in a Swedish first league according to this study. Although the injury incidence seems to be slightly lower than in adult elite players the injuries seem to be more traumatic in elite youth players.

\section{CONFLICT OF INTEREST}

No potential conflict of interest relevant to this article was reported.

\section{REFERENCES}

Brink MS, Visscher C, Arends S, Zwerver J, Post WJ, Lemmink KA. Monitoring stress and recovery: new insights for the prevention of injuries and illnesses in elite youth soccer players. Br J Sports Med 2010;44:809815.

Brito J, Malina RM, Seabra A, Massada JL, Soares JM, Krustrup P, Rebelo A. Injuries in Portuguese youth soccer players during training and match play. J Athl Train 2012;47:191-197.

Clausen MB, Zebis MK, Møller M, Krustrup P, Hölmich P, Wedderkopp $\mathrm{N}$, Andersen LL, Christensen KB, Thorborg K. High injury incidence in adolescent female soccer. Am J Sports Med 2014;42:2487-2494.

Daniel DM, Stone ML, Dobson BE, Fithian DC, Rossman DJ, Kaufman KR. Fate of the ACL-injured patient. A prospective outcome study. Am J Sports Med 1994;22:632-644.

Ekstrand J, Gillquist J. Soccer injuries and their mechanisms: a prospective study. Med Sci Sports Exerc 1983;15:267-270.

Ekstrand J, Hägglund M, Waldén M. Injury incidence and injury patterns in professional football: the UEFA injury study. Br J Sports Med 2011; 45:553-558.

Ekstrand J, Roos H, Tropp H. Normal course of events amongst Swedish soccer players: an 8-year follow-up study. Br J Sports Med 1990;24: 117-119.

Emery CA, Meeuwisse WH. The effectiveness of a neuromuscular prevention strategy to reduce injuries in youth soccer: a cluster-randomised controlled trial. Br J Sports Med 2010;44:555-562.

Emery CA, Meeuwisse WH, Hartmann SE. Evaluation of risk factors for injury in adolescent soccer: implementation and validation of an injury surveillance system. Am J Sports Med 2005;33:1882-1891.

Ergün M, Denerel HN, Binnet MS, Ertat KA. Injuries in elite youth football players: a prospective three-year study. Acta Orthop Traumatol Turc 2013;47:339-346.

FIFA Communications Division Information Services. FIFA big count 2006: 270 million people active in football. Zurich; FIFA; 2007. 
Ford PR, Ward P, Hodges NJ, Williams AM. The role of deliberate practice and play in career progression in sport: the early engagement hypothesis. High Abil Stud 2009;20:65-75.

Froholdt A, Olsen OE, Bahr R. Low risk of injuries among children playing organized soccer: a prospective cohort study. Am J Sports Med 2009;37:1155-1160.

Fuller CW, Ekstrand J, Junge A, Andersen TE, Bahr R, Dvorak J, Hägglund M, McCrory P, Meeuwisse WH. Consensus statement on injury definitions and data collection procedures in studies of football (soccer) injuries. Scand J Med Sci Sports 2006;16:83-92.

Gillquist J, Messner K. Anterior cruciate ligament reconstruction and the long-term incidence of gonarthrosis. Sports Med 1999;27:143-156.

Hägglund M, Waldén M, Bahr R, Ekstrand J. Methods for epidemiological study of injuries to professional football players: developing the UEFA model. Br J Sports Med 2005a;39:340-346.

Hägglund M, Waldén M, Ekstrand J. Injury incidence and distribution in elite football: a prospective study of the Danish and the Swedish top divisions. Scand J Med Sci Sports 2005b;15:21-28.

Le Gall F, Carling C, Reilly T. Biological maturity and injury in elite youth football. Scand J Med Sci Sports 2007;17:564-572.

Le Gall F, Carling C, Reilly T, Vandewalle H, Church J, Rochcongar P. Incidence of injuries in elite French youth soccer players: a 10-season study. Am J Sports Med 2006;34:928-938.

Lohmander LS, Ostenberg A, Englund M, Roos H. High prevalence of knee osteoarthritis, pain, and functional limitations in female soccer players twelve years after anterior cruciate ligament injury. Arthritis Rheum 2004;50:3145-3152.

Mohib M, Moser N, Kim R, Thillai M, Gringmuth R. A four year prospective study of injuries in elite Ontario youth provincial and national soccer players during training and matchplay. J Can Chiropr Assoc

\section{4;58:369-376.}

Price RJ, Hawkins RD, Hulse MA, Hodson A. The Football Association medical research programme: an audit of injuries in academy youth football. Br J Sports Med 2004;38:466-471.

Slavotinek JP. Muscle injury: the role of imaging in prognostic assignment and monitoring of muscle repair. Semin Musculoskelet Radiol 2010;14:194-200.

Timpka T, Risto O, Björmsjö M. Boys soccer league injuries: a community-based study of time-loss from sports participation and long-term sequelae. Eur J Public Health 2008;18:19-24.

van der Sluis A, Elferink-Gemser MT, Coelho-e-Silva MJ, Nijboer JA, Brink MS, Visscher C. Sport injuries aligned to peak height velocity in talented pubertal soccer players. Int J Sports Med 2014;35:351-355.

von Porat A, Roos EM, Roos H. High prevalence of osteoarthritis 14 years after an anterior cruciate ligament tear in male soccer players: a study of radiographic and patient relevant outcomes. Ann Rheum Dis 2004; 63:269-273.

Waldén M, Hägglund M, Ekstrand J. Injuries in Swedish elite football: a prospective study on injury definitions, risk for injury and injury pattern during 2001. Scand J Med Sci Sports 2005a;15:118-125.

Waldén M, Hägglund M, Ekstrand J. UEFA Champions League study: a prospective study of injuries in professional football during the 20012002 season. Br J Sports Med 2005b;39:542-546.

Weatherall PT, Crues JV 3rd. Musculotendinous injury. Magn Reson Imaging Clin N Am 1995;3:753-772.

Woods C, Hawkins R, Hulse M, Hodson A. The Football Association Medical Research Programme: an audit of injuries in professional football-analysis of preseason injuries. Br J Sports Med 2002;36:436441. 